\title{
Cytoprotective Effects of Cell-Permeable Bifunctional Antioxidant Enzyme, GST-TAT-SOD, against Cisplatin-Induced Cell Damage
}

\author{
Jianru Pan, ${ }^{1}$ Lingling Li, ${ }^{1}$ Lili Liang, ${ }^{1,2}$ Huocong He, ${ }^{3,4}$ Ying Su, ${ }^{3,4}$ Xiangling Wang, \\ and Shutao Liu ${ }^{1}$ \\ ${ }^{1}$ College of Biological Science and Engineering, Fuzhou University, No. 2 Xue Yuan Road, University Town, Fuzhou, \\ Fujian 350108, China \\ ${ }^{2}$ Euler Genomics (Beijing) Co., Ltd., No.8 Life Science Park Road, Zhongguancun Life Science Park, Beijing 102206, China \\ ${ }^{3}$ Laboratory of Radiation Oncology and Radiobiology, Fujian Cancer Hospital \& Fujian Medical University Cancer Hospital, Fuzhou, \\ Fujian 350014, China \\ ${ }^{4}$ Fujian Key Laboratory of Tumor Translational Cancer Medicine, Fuzhou, Fujian 350014, China
}

Correspondence should be addressed to Jianru Pan; panjr@fzu.edu.cn

Received 5 May 2017; Revised 30 July 2017; Accepted 29 August 2017; Published 30 November 2017

Academic Editor: Jacek Zielonka

Copyright (c) 2017 Jianru Pan et al. This is an open access article distributed under the Creative Commons Attribution License, which permits unrestricted use, distribution, and reproduction in any medium, provided the original work is properly cited.

\begin{abstract}
GST-TAT-SOD, a cell-permeable bifunctional antioxidant enzyme, is a potential selective radioprotector. This study aimed to investigate the cytoprotective activity of GST-TAT-SOD against cisplatin-induced damage. The current study showed that cisplatin induced the formation of reactive oxygen species in normal L-02 cells. GST-TAT-SOD (2000 U/mL) executed its antioxidant role by directly scavenging excess intracellular free radicals and augmenting cellular antioxidant defense such as reducing MDA level, enhancing the SOD activity, GST activity, and T-AOC. Thus, it suppressed the growth inhibition and apoptosis of cisplatin-treated normal cells. Meanwhile, the growth inhibition of tumor cells (SMMC-7721) caused by cisplatin was unaffected by GST-TAT-SOD pretreatment. GST-SOD, as a comparison, seemed to be powerless for related indicators as it could not enter into cells without cell-permeating peptide. These results suggest that GST-TAT-SOD might be a potential cytoprotective agent for cisplatin-induced side effects.
\end{abstract}

\section{Introduction}

Cisplatin, cis-diamminedichloroplatinum (II) or CDDP, is the most potent chemotherapy drugs widely used against the spread of solid tumors including tumors of the ovary, cervix, bladder, lung, head, and neck in adults [1,2]. Clinical success of cisplatin and its derivatives determines considerable effort to develop other effective metal-based anticancer compounds [3-5]. However, its side effects in normal tissues limit its clinical application. These side effects which are also observed at therapeutic doses include gastrointestinal effects (e.g., nausea and vomiting), bone marrow suppression, ototoxicity, neurotoxicity (e.g., peripheral neuropathy), hepatotoxicity, and genotoxicity [6].

The mechanism of action of cisplatin is mainly based on DNA damage. It enters into cells, binds to DNA, and, consequently, induces apoptosis and inhibits cell growth [7]. Most metals can generate reactive oxygen species (ROS). Except for DNA damage, many data suggest that cisplatin also induces ROS that trigger cell death [8-11]. The ROS levels depend on the concentration of cisplatin and the duration of exposure [12]. It is reported that cisplatin-induced ROS is responsible for the severe side effects of cisplatin therapy such as hepatotoxicity [12].

In this direction, as safeguards against the accumulation of ROS, antioxidant enzymes would be a kind of promising protector against cisplatin-induced injury. Superoxide dismutases (SODs) catalyze the dismutation of superoxide into oxygen $\left(\mathrm{O}_{2}\right)$ or hydrogen peroxide $\left(\mathrm{H}_{2} \mathrm{O}_{2}\right)$ and serve key antioxidant roles as superoxide is one of the main reactive oxygen species in the cells. However, they are hard to enter into the cells due to their large molecular weights. Protein 
transduction domain (PTD) TAT (YGRKKRRQRRR) derived from HIV-1 Tat protein can carry larger molecules such as oligonucleotides and full-length proteins across cellular membranes and has been proven useful in delivering biologically active cargoes both in vitro and in vivo models [13].

Therefore, in our previous works, we constructed cellpermeable monofunctional antioxidant enzyme SOD-TAT with the fusion of human CuZn-SOD and TAT peptide [14]. We reported that SOD-TAT has a significant protective effect on radiation side effect induced by extra ROS both in vitro and in vivo $[15,16]$. To eliminate more types of free-radical species induced by irradiation, glutathione Stransferase (GST) was further inserted into the fusion protein and formed a bifunctional antioxidant enzyme GST-TATSOD. GSTs catalyze the conjugation of the reduced form of glutathione (GSH) to xenobiotic substrates for detoxification. As expected, GST-TAT-SOD has a better radioprotective effect than SOD-TAT [16]. The former represents remarkable protective effects on irradiated normal liver cells and minimal effect on irradiated hepatoma cells [16]. Moreover, we recently reported that GST-TAT-SOD has an overall protective effect on the whole body-irradiated mice [17].

The current study investigated the cytoprotective effects of GST-TAT-SOD against cisplatin-induced cell damage.

\section{Materials and Methods}

2.1. Materials. E.coli strains with the recombinant plasmid of GST-TAT-SOD and GST-SOD were obtained from the Institute of Biotechnology, Fuzhou University (Fujian, China). Malondialdehyde (MDA), SOD, total antioxidant capacity (T-AOC), and glutathione S-transferase (GST) reagent kits were purchased from Nanjing Jiancheng Bioengineering Co. Ltd. (Jiangsu, China). Micro BCA ${ }^{\mathrm{TM}}$ Protein Assay Kit was purchased from Thermo Scientific (USA). RPMI 1640 and fetal bovine serum were purchased from HyClone and Gibco (USA), respectively. Methyl thiazolyl tetrazolium (MTT) and 2', $7^{\prime}$-dichlorodihydrofluorescein diacetate (DCFH-DA) were purchased from Sigma (USA). FITC Annexin $\mathrm{V}$ apoptosis detection kit was purchased from BD Pharmingen (USA). Cisplatin was purchased from Haosen Pharmaceutical Group Co., Ltd. (Jiangsu, China). All other chemicals were of analytical purity.

2.2. Cell Cultures. Human normal liver cell line L-02 and hepatoma cell line SMMC-7721 are available from Shanghai Institute of Biochemistry and Cell Biology (SIBCB). Cells were cultured in RPMI 1640 (HyClone), supplemented with $10 \%$ fetal bovine serum (Gibco), $100 \mathrm{U} / \mathrm{ml}$ penicillin and $100 \mathrm{mg} / \mathrm{ml}$ streptomycin (Gibco) at $37^{\circ} \mathrm{C}$ in a $5 \% \mathrm{CO}_{2}$ humidified chamber.

2.3. Preparation of GST-TAT-SOD. GST-TAT-SOD and GST-SOD were prepared according to the method of our previous work [16]. The concentration, SOD activity, and GST activity of the purified proteins were determined by BCA protein assay kit (Thermo, USA), SOD, and GST reagent kits (Jiangsu, China), respectively. The SOD activity and GST activity of purified GST-TAT-SOD were
$2476 \mathrm{U} / \mathrm{mL}$ and $766 \mathrm{U} / \mathrm{mL}$, respectively. Purified proteins were concentrated and dialyzed for subsequent experiments.

2.4. Cytotoxicity Assay. MTT, 3-[4,5-dimethylthiazol-2-yl]2,5-diphenyl tetrazolium bromide, is reduced by active mitochondrial dehydrogenases of living cells to formazan. The conversion can be measured at $570 \mathrm{~nm}$ spectrophotometrically. Nearly $2 \times 10^{5} \mathrm{~L}-02$ cells and SMMC-7721 cells were seeded per well in 96-well plates. Then, cells were treated with various concentrations of GST-TAT-SOD or GSTSOD. After incubation for $3 \mathrm{~h}, 0.7 \mu \mathrm{g} / \mathrm{mL}$ cisplatin was added to each well and incubated for $24 \mathrm{~h}$ (three replicates each). Then, cell viability was calculated by a colorimetric assay using MTT (Sigma, USA).

2.5. Biochemical Estimations. L-02 cells in logarithmic growth phase were trypsinized and counted with a hemocytometer. Approximately $1.75 \times 10^{5}$ cells were seeded into $75 \mathrm{~cm}^{2}$ flasks. The experiments were performed in triplicate, and tests were carried out on the following different cell groups. The first group $(\mathrm{CON})$ was untreated and the second group (CDDP) was treated with $0.7 \mu \mathrm{g} / \mathrm{mL}$ cisplatin alone. GTS + CDDP group and GS + CDDP group were pretreated with indicated concentrations of GST-TAT-SOD or GSTSOD, respectively, for $3 \mathrm{~h}$ before injured by cisplatin.

After adding cisplatin, cells were further cultured for $24 \mathrm{~h}$ at $37^{\circ} \mathrm{C}$. Then, cells were lysed using PBS containing $0.5 \%$ Triton X-100. The cell lysates were removed and centrifuged at $13,000 \mathrm{rpm}$ for $15 \mathrm{~min}$ at $4^{\circ} \mathrm{C}$. The SOD activity, GST activity, T-AOC, and MDA level in the supernatants were determined using their corresponding diagnostic reagent kits (Nanjing Jiancheng Bioengineering) spectrophotometrically according to the manufacturer's instructions. The protein contents of the lysates were determined by using BCA protein assay kit (Thermo, USA).

2.6. ROS Assay. The conversion of DCHF-DA (Sigma, USA) was used to assess the production of endogenous total ROS [18]. Cells (approximately $1.75 \times 10^{5}$ cells per well) were plated in triplicate, grouped as described in section 2.5 , pretreated with or without proteins, and treated with $0.7 \mu \mathrm{g} / \mathrm{mL}$ cisplatin for $24 \mathrm{~h}$. After incubation, cells were rinsed with PBS, added $10 \mu \mathrm{M} \mathrm{DCFH}-\mathrm{DA}$, and incubated for $0.5 \mathrm{~h}$ at $37^{\circ} \mathrm{C}$.

Then, cells from the different groups were lysed as described in Section 2.5 and the fluorescence in the supernatants were read with a Synergy H4 Hybrid Multi-Mode Microplate Reader (BioTek Instruments, Winooski, VT, USA). The protein contents of the cell lysates were determined by BCA protein assay kit (Thermo, USA) following the manufacturer's directions. Fluorescence was corrected for background signal and normalized for protein content and expressed as fluorescence/mg protein.

2.7. Apoptosis Assays. Approximately $7 \times 10^{5}$ cells were seeded into $75 \mathrm{~cm}^{2}$ flasks and grouped as described in Section 2.5 . Then, cells were pretreated with or without proteins and incubated for $24 \mathrm{~h}$ with $0.7 \mu \mathrm{g} / \mathrm{mL}$ cisplatin. Apoptotic cells were identified by the Annexin V-FITC Apoptosis Detection Kit (BD Pharmingen, San Diego, CA, USA) according to the manufacturer's instructions using a FACScan flow cytometer. 


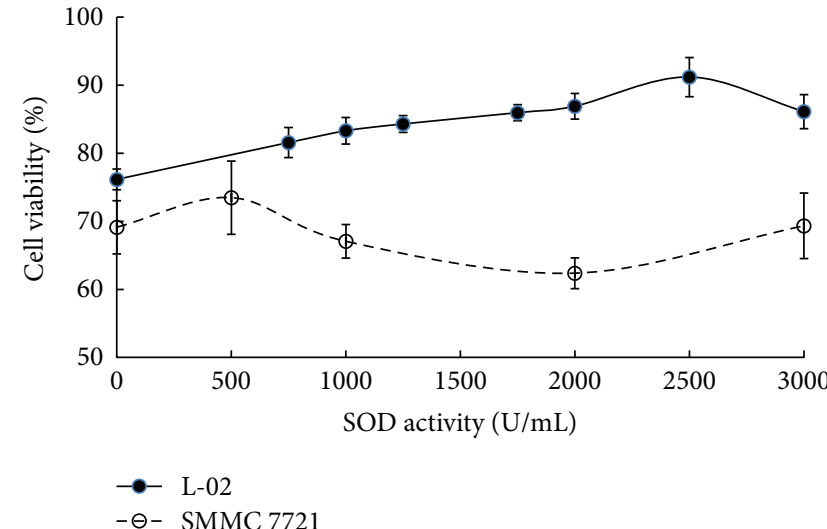

(a)

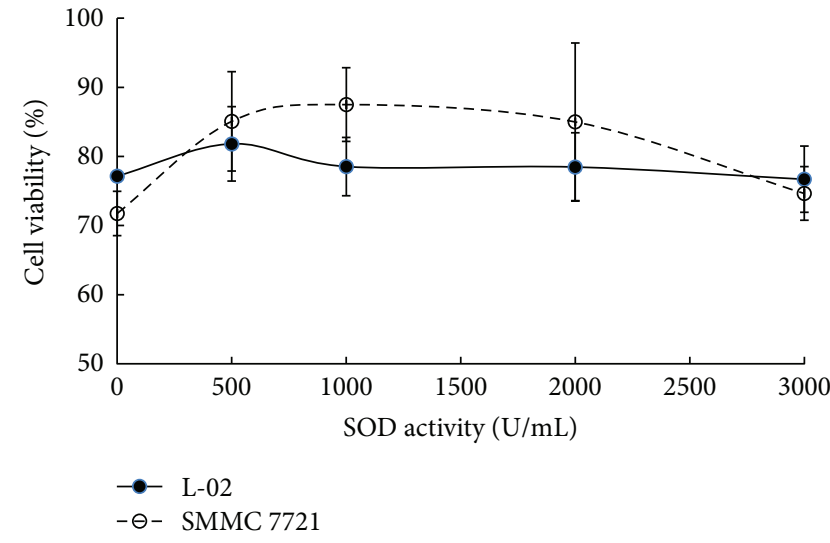

(b)

FIGURE 1: Biological effect of fusion proteins on the cell viability of cisplatin-treated cells. Nearly $2 \times 10^{5}$ cells were seeded per well in 96 -well plates and treated with various concentrations of GST-TAT-SOD (a) or GST-SOD (b). After incubation for $3 \mathrm{~h}, 0.7 \mu \mathrm{g} / \mathrm{mL}$ cisplatin was added to each well and incubated for $24 \mathrm{~h}$ (three replicates each). The bars indicate the means $\pm \mathrm{SD}(n=3)$.

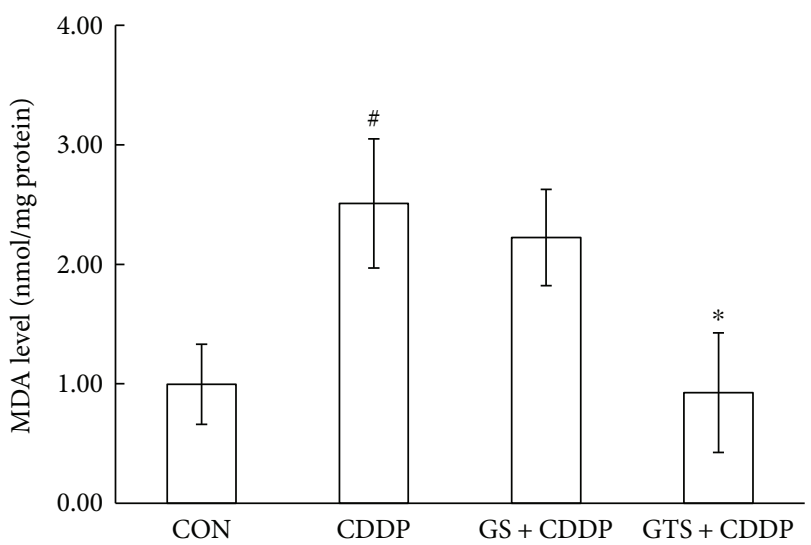

(a)

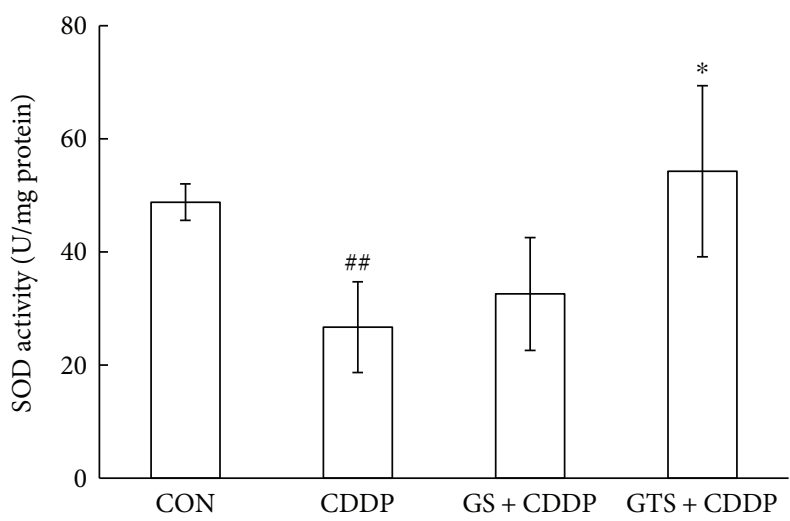

(c)

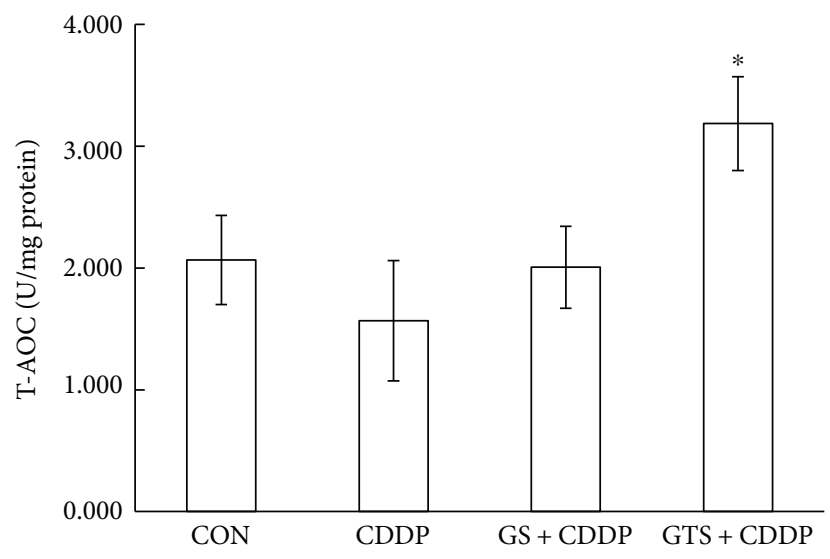

(b)

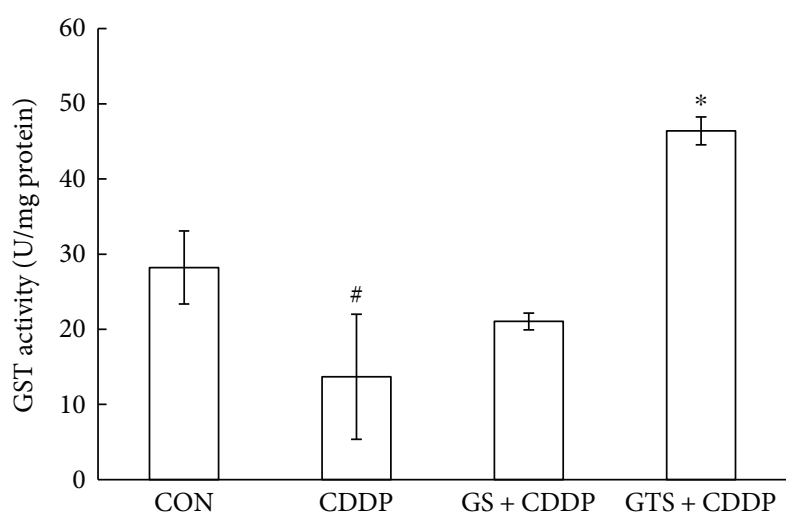

(d)

FIGURE 2: Biochemical estimations of L-02 cells treated with cisplatin. (a) MDA level, (b) T-AOC, (c) SOD activity, and (d) GST activity. Cells were treated with protein $(2000 \mathrm{U} / \mathrm{mL})$ for $3 \mathrm{~h}$ followed by $0.7 \mu \mathrm{g} / \mathrm{mL}$ cisplatin. After treatment, the cells were further cultured for $24 \mathrm{~h}$ at $37^{\circ} \mathrm{C}$. Then, the cells were lysed and centrifuged, and the antioxidant activities and protein contents in the supernatants were determined subsequently. The bars indicate the means \pm SD $(n=3)$. The CDDP group was compared with the control group $\left({ }^{\#} P<0.05,{ }^{\#} P<0.01\right)$. The pretreated group was compared with the CDDP group $\left({ }^{*} \mathrm{P}<0.05\right)$. 
2.8. Statistical Analysis. Statistical analysis of all data was performed using Excel. The results are reported as means \pm S.E. or S.E.M. The $P$ values were determined using the Student two-tailed $t$-test, and $P<0.05$ or $P<0.01$ was considered statistically significant.

\section{Results}

3.1. Biological Effect of GST-TAT-SOD on the Cell Viability of Cisplatin-Treated Cells. It can be seen from Figure 1 that GST-TAT-SOD shows an entirely different biological effect on normal cells or cancer cells injured by cisplatin. It had a protective role in L-02 cells against the cytotoxicity induced by cisplatin (Figure 1(a)). We found that the percentage of viable cells increased continuously among L-02 cells at lower doses of GST-TAT-SOD, the maximal vitality increased by about $15 \%$ at $2500 \mathrm{U} / \mathrm{mL}$, and a progressive decrease in cell viability at higher protein concentrations. By contrast, GST-TAT-SOD had little effect on the cell viability of cisplatin-treated SMMC-7721 cells (Figure 1(a)). They presented minimal viability decreased by about $7 \%$ at $2000 \mathrm{U} / \mathrm{mL}$ GST-TAT-SOD pretreatment. To sum up, $2000 \mathrm{U} / \mathrm{mL}$ GST-TAT-SOD pretreatment could reduce the growth inhibition of L-02 cells induced by cisplatin while that of SMMC-7721 cells were enhanced in the meantime. Hence, $2000 \mathrm{U} / \mathrm{mL}$ GST-TAT-SOD pretreatment was used in the experiments. Compared with GST-TAT-SOD, GST-SOD seemed to provide better protection for cisplatin-treated SMMC-7721 cells than L-02 cells (Figure 1(b)).

3.2. Biochemical Estimations. As is shown in Figure 2, reductions in the activity of SOD $(P<0.01)$, GST $(P<0.05)$, and T-AOC $(P>0.05)$ and a significant increase in the level of MDA $(P<0.05)$ were observed in the CDDP group $24 \mathrm{~h}$ after cisplatin treatment. GST-TAT-SOD pretreatment remarkably decreased the level of MDA by about 63\% $(P<0.05)$, enhanced the SOD activity by about $103 \%(P<0.05)$, GST activity by about $239 \%(P<0.05)$, and T-AOC by about $103 \%(P<0.05)$ of cisplatin-damaged cells. GST-SOD pretreatment seemed to be slightly protective on these indicators, but there was no significance between the CDDP group and GS + CDDP group.

3.3. ROS Assay. Total ROS in L-02 cells induced by cisplatin was evaluated using DCFH-DA. A significant enhancement by about $51 \%$ in ROS was observed in the cells after cisplatin treatment as is shown in Figure $3(P<0.01)$. GST-SOD pretreatment reduced the extra ROS by about $11 \%(P<0.05)$ while that of GST-TAT-SOD pretreatment reduced by about $25 \%(P<0.05)$.

3.4. Apoptotic Index. To explore whether GST-TAT-SOD could protect L-02 cells against cisplatin-induced apoptosis, Annexin V/PI staining was performed using flow cytometric analysis. As is shown in Figure 4, compared with the CON group, the total apoptotic rate of the CDDP group increased by about $90 \%$. GST-TAT-SOD pretreatment lowered the total apoptotic rate in cisplatin-injured cells by $27 \%$, while GST-SOD pretreatment seemed to be invalid.

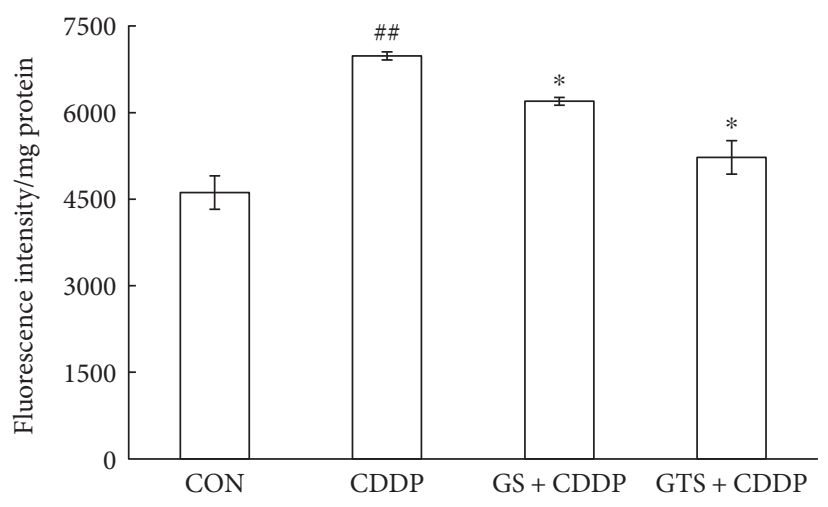

FIgURE 3: DCFH-DA detection of total ROS in L-02 cells treated with cisplatin. Cells were plated in triplicate, pretreated with or without proteins, and treated with $0.7 \mu \mathrm{g} / \mathrm{mL}$ cisplatin for $24 \mathrm{~h}$. After incubation, cells were washed with PBS and incubated with $10 \mu \mathrm{M}$ DCFH-DA for $0.5 \mathrm{~h}$ at $37^{\circ} \mathrm{C}$. Fluorescence was corrected for background signal and normalized for protein content and expressed as fluorescence/mg of protein. The bars indicate the means $\pm \mathrm{SD}(n=3)$. The CDDP group was compared with the control group (\#\# $P<0.01$ ). The pretreated group was compared with the CDDP group $\left({ }^{*} P<0.05\right)$.

\section{Discussion}

Cisplatin is a widely used chemotherapy agent against many solid tumors. However, the dose-independent side effects including ototoxicity, neurotoxicity, and hepatotoxicity placed a health and economic burden on patients [6]. Although the exact mechanism of cisplatin toxicity is not fully understood, multiple studies have shown that the failure of cisplatin-induced DNA damage repair ultimately results in cell death. Besides, the formation of cisplatin-induced ROS and oxidative stress also lead to apoptosis [8-11]. It is reported that antioxidants such as vitamin E, carotenoids, GSH, phytoestrogens, phenols, and polyphenols can prevent the cisplatin-induced mitochondrial production of ROS [19-21]. In that case, enzymatic antioxidants like SOD, catalase (CAT), glutathione peroxidase $(\mathrm{GPx})$, and GST would be more efficient.

We constructed a cell-permeable bifunctional antioxidant enzyme GST-TAT-SOD in our previous works. GSTTAT-SOD retains more than $90 \%$ of the enzyme activity under physiological conditions [22]. It can enter into cells by the transduction with TAT-PTD in an active form, scavenge excess production of ROS, balance intracellular oxidant-antioxidant status, and protect the cells against irradiation damage [16]. Besides that, GST-TAT-SOD can effectively transduce into tissues such as the spleen and liver without affecting tissular antioxidant indices and protect normal tissues from radiation damage $[16,17]$.

Since ROS is one of the causes of cisplatin damage, we wondered whether GST-TAT-SOD could provide a protective effect against cisplatin damage too. In this study, DCFH-DA was used to evaluate intracellular ROS level. Although DCFH-DA was found to be unsuitable for direct detection of specific ROS [23], it can be used as a reference for a global amount of ROS combined with other relevant 


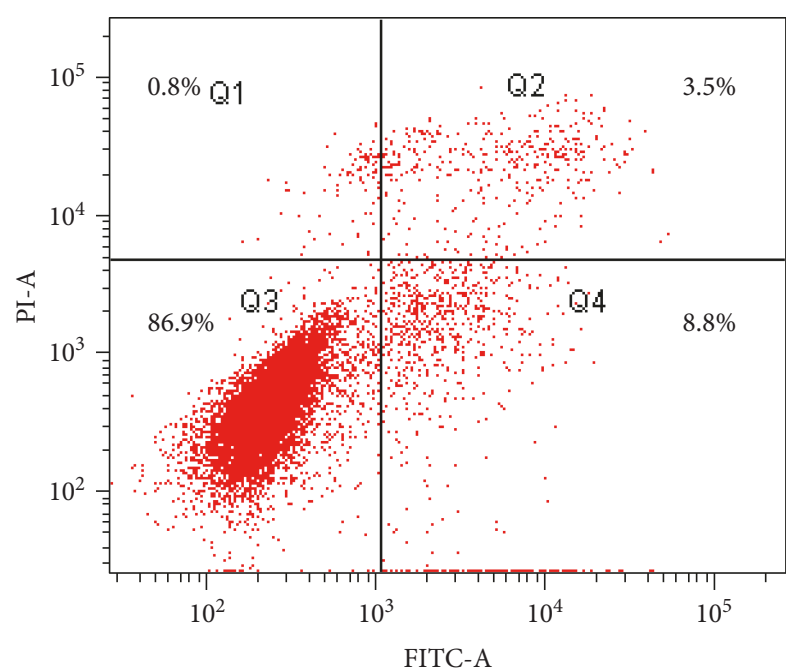

(a)

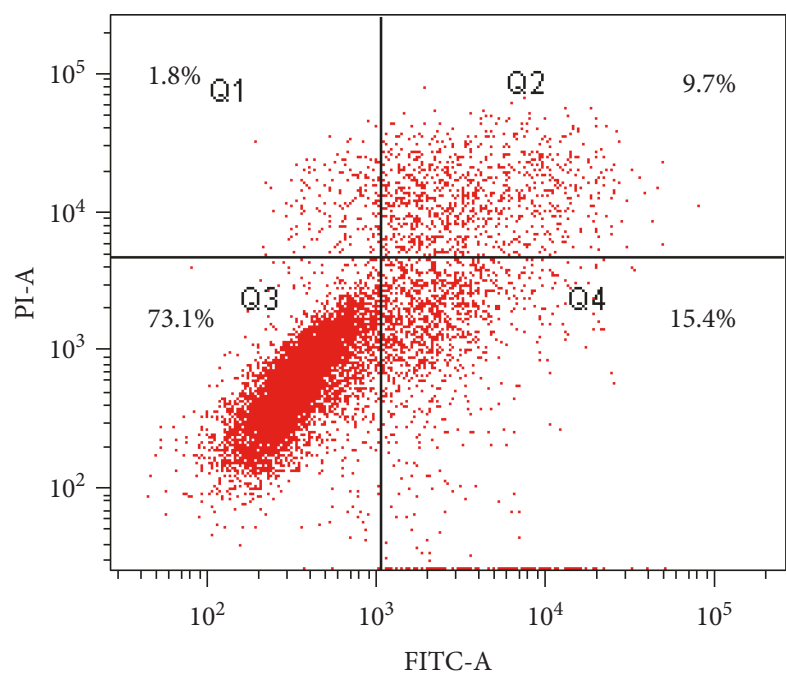

(c)

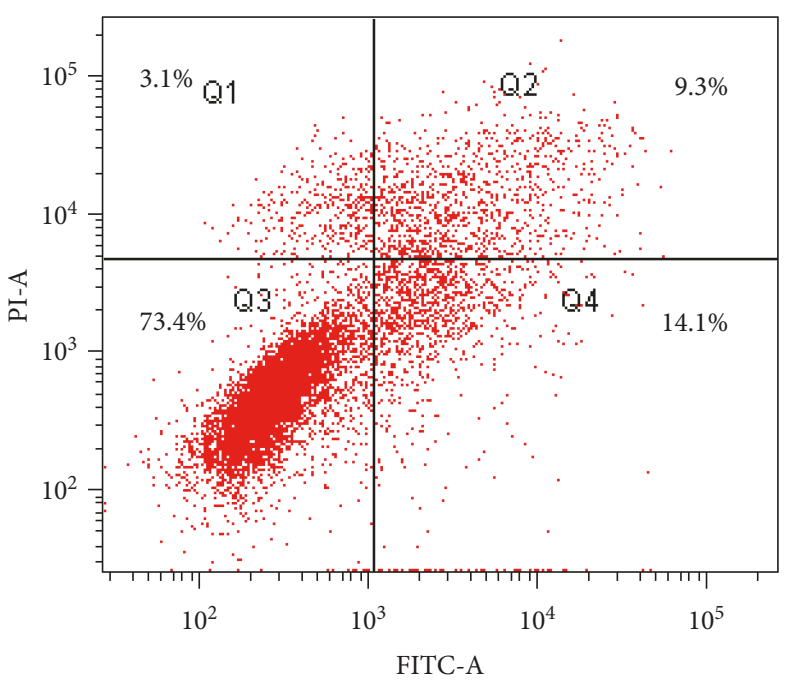

(b)

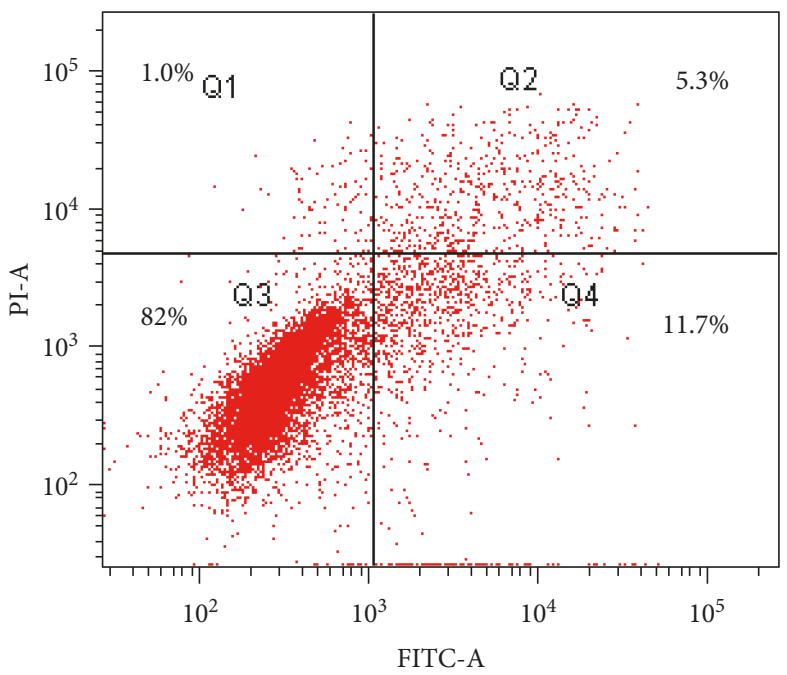

(d)

FIgURE 4: Annexin V/PI analysis of apoptosis in L-02 cells at $24 \mathrm{~h}$ after treatment with $0.7 \mu \mathrm{g} / \mathrm{mL}$ cisplatin. Cells were stained with Annexin V FITC and PI and detected by flow cytometry. The lower right quadrant (Annexin V+ PI-) represents early apoptosis, whereas the upper right quadrant (Annexin V+ PI+) represents late apoptosis. (a) CON, (b) CDDP, (c) GS + CDDP, and (d) GTS + CDDP.

indicators such as MDA level. MDA level is an indicator of lipid peroxidation and commonly known as a marker of oxidative stress and the increment of free radicals [24]. A remarkable increase of DCF fluorescence and MDA level was observed in the cisplatin-injured L-02 cells, indicating the formation of extra ROS as described in other literature [8-11] (Figures 2(a) and 3). GST-TAT-SOD significantly reduced the elevation of ROS in cisplatin-injured L-02 cells (Figures 2(a) and 3). The SOD activity and GST activity of GST-TAT-SOD pretreated cells both were remarkably increased compared with the cells of the CDDP group. Except for the enhancement of two enzymatic antioxidants, the T-AOC of GST-TAT-SOD pretreated cells was also remarkably elevated. As an important integrative index, T-AOC reflects the total antioxidant capacity in the cells including both enzymatic and nonenzymatic antioxidants. It indicated that bifunctional GST-TAT-SOD could provide comprehensive protection of the endogenous antioxidant system. Therefore, subsequent repression of the growth inhibition and apoptosis in GST-TAT-SOD pretreated cells was not in doubt as the excessive production of intracellular ROS and oxidative stress could lead to apoptosis [8-11] (Figures 1 and 4). GST-SOD, by contrast, gave a much weaker protection effect on all indicators as it could not enter into cells without cell-permeating peptide (Figures 1-4).

The family of GSTs is part of a cellular Phase II detoxification enzymes. Their catalytic functions are conjugating GSH with a diverse range of electrophilic substrates [25]. Thus, they are described for their roles in detoxification and linkage of their expression levels with high cancer drug resistance is thought to reflect enhanced capabilities in breaking down drugs to noncytotoxic metabolites, although no entire cogent explanation for these correlations exists [26, 27]. So, 
whether the ability of GST-TAT-SOD to significantly enhance GST activity in cisplatin-injured normal cells would lead to tumor resistance to cisplatin?

Our previous works indicated that GST-TAT-SOD is a potent radioprotector for normal cells while making no significant effects on irradiated tumor cells meanwhile [16]. The selectively protected effect of GST-TAT-SOD was observed in the present study again. GST-TAT-SOD suppressed the growth inhibition of normal cells induced by cisplatin at the dose of $2000 \mathrm{U} / \mathrm{mL}$ and simultaneously enhanced that of tumor cells (Figure 1).

All of the above suggest that bifunctional GST-TAT-SOD can significantly reduce the chemotherapy- or radiationinduced side effects without impairing the antitumor efficacy of the two therapies. Further studies are needed to confirm the more exact protective mechanism of GST-TAT-SOD for a comprehensive assessment of its potential as an adjunctive therapy with various cancer treatments.

\section{Conclusions}

In summary, this study has demonstrated that GST-TATSOD protects normal cells from cisplatin-induced damages as it can decrease extra ROS, maintain the cellular antioxidant system, and suppress the growth inhibition and apoptosis. Furthermore, it does not alter cisplatin-induced cytotoxicity to cancer cells. This dual activity is necessary for a drug to be considered an effective adjunctive therapy for various cancer treatments.

\section{Conflicts of Interest}

The authors declare that there is no conflict of interests regarding the publication of this paper.

\section{Acknowledgments}

The financial support provided by grants from the National Natural Science Foundation of China (81472907), the Fujian Social Development Guidance (key) Project (2014Y0014), and the Natural Science Foundation of Fujian Province (2015J01135).

\section{References}

[1] L. Kelland, "The resurgence of platinum-based cancer chemotherapy," Nature Reviews Cancer, vol. 7, no. 8, pp. 573-584, 2007.

[2] M. J. van den Bent, M. E. Hegi, and R. Stupp, "Recent developments in the use of chemotherapy in brain tumours," European Journal of Cancer, vol. 42, no. 5, pp. 582-588, 2006.

[3] M. Frezza, S. Hindo, D. Chen et al., "Novel metals and metal complexes as platforms for cancer therapy," Current Pharmaceutical Design, vol. 16, no. 16, pp. 1813-1825, 2010.

[4] C. M. Che and F. M. Siu, "Metal complexes in medicine with a focus on enzyme inhibition," Current Opinion in Chemical Biology, vol. 14, no. 2, pp. 255-261, 2010.

[5] D. Chen, V. Milacic, M. Frezza, and Q. Dou, "Metal complexes, their cellular targets and potential for cancer therapy," Current Pharmaceutical Design, vol. 15, no. 7, pp. 777-791, 2009.
[6] M. H. Hanigan and P. Devarajan, "Cisplatin nephrotoxicity: molecular mechanisms," Cancer Therapy, vol. 1, pp. 47-61, 2003.

[7] Y. Sedletska, M. J. Giraudpanis, and J. M. Malinge, "Cisplatin is a DNA-damaging antitumour compound triggering multifactorial biochemical responses in cancer cells: importance of apoptotic pathways," Current Medicinal Chemistry-AntiCancer Agents, vol. 5, no. 3, pp. 251-265, 2005.

[8] S. Amptoulach and N. Tsavaris, "Neurotoxicity caused by the treatment with platinum analogues," Chemotherapy Research and Practice, vol. 2011, Article ID 843019, 5 pages, 2011.

[9] A. Naqshbandi, W. Khan, S. Rizwan, and F. Khan, "Studies on the protective effect of flaxseed oil on cisplatin-induced hepatotoxicity," Human \& Experimental Toxicology, vol. 31, no. 4, p. 364, 2012.

[10] B. I. Ognjanović, N. Z. Djordjević, M. M. Matić et al., "Lipid peroxidative damage on cisplatin exposure and alterations in antioxidant defense system in rat kidneys: a possible protective effect of selenium," International Journal of Molecular Sciences, vol. 13, no. 2, pp. 1790-1803, 2012.

[11] H. Matsushima, K. Yonemura, K. Ohishi, and A. Hishida, "The role of oxygen free radicals in cisplatin-induced acute renal failure in rats," The Journal of Laboratory and Clinical Medicine, vol. 131, no. 6, pp. 518-526, 1998.

[12] A. Brozovic and R. A. M. Ambriovic, "The relationship between cisplatin-induced reactive oxygen species, glutathione, and BCL-2 and resistance to cisplatin," Critical Reviews in Toxicology, vol. 40, no. 4, p. 347, 2010.

[13] A. van den Berg and S. F. Dowdy, "Protein transduction domain delivery of therapeutic macromolecules," Current Opinion in Biotechnology, vol. 22, no. 6, pp. 888-893, 2011.

[14] J. Pan, K. Zhou, G. Zheng, S. Liu, and P. Rao, "Crystallization and preliminary X-ray diffraction analysis of the SOD-TAT fusion protein," Acta Crystallographica Section F: Structural Biology Communications, vol. 68, Part 5, pp. 543-546, 2012.

[15] J. Pan, Y. Su, X. Hou et al., "Protective effect of recombinant protein SOD-TAT on radiation-induced lung injury in mice," Life Sciences, vol. 91, no. 3-4, pp. 89-93, 2012.

[16] J. Pan, H. He, Y. Su et al., "GST-TAT-SOD: cell permeable bifunctional antioxidant enzyme-a potential selective radioprotector," Oxidative Medicine and Cellular Longevity, vol. 2016, Article ID 5935080, 13 pages, 2016.

[17] J. Pan, H. He, Y. Su et al., "In vivo radioprotective activity of cell permeable bifunctional antioxidant enzyme GST-TATSOD against whole body ionizing irradiation in mice," Oxidative Medicine and Cellular Longevity, vol. 2017, Article ID 2689051, 9 pages, 2017.

[18] O. Myhre, J. M. Andersen, H. Aarnes, and F. Fonnum, "Evaluation of the probes $2^{\prime}, 7^{\prime}$-dichlorofluorescin diacetate, luminol, and lucigenin as indicators of reactive species formation," Biochemical Pharmacology, vol. 65, no. 10, pp. 1575-1582, 2003.

[19] P. Mukhopadhyay, B. Horvath, Z. Zsengeller et al., "Mitochondrial-targeted antioxidants represent a promising approach for prevention of cisplatin-induced nephropathy," Free Radical Biology \& Medicine, vol. 52, no. 2, pp. 497-506, 2012.

[20] M. Nematbakhsh, F. Ashrafi, T. Safari et al., "Administration of vitamin $\mathrm{E}$ and losartan as prophylaxes in cisplatin-induced nephrotoxicity model in rats," Journal of Nephrology, vol. 25, no. 3, pp. 410-417, 2011. 
[21] S. Hajian, M. Rafieian-Kopaei, and H. Nasri, "Renoprotective effects of antioxidants against cisplatin nephrotoxicity," Journal of Nephropharmacology, vol. 3, no. 2, pp. 39-42, 2014.

[22] J. R. Pan, G. J. Zheng, W. B. Huang, J. D. Zhang, S. T. Liu, and P. F. Rao, "Stability comparison of SOD from different sources," Journal of Fuzhou University(Natural Science Edition), vol. 37, no. 5, pp. 756-759, 2009.

[23] B. Kalyanaraman, V. Darley-Usmar, K. J. Davies et al., "Measuring reactive oxygen and nitrogen species with fluorescent probes: challenges and limitations," Free Radical Biology \& Medicine, vol. 52, no. 1, pp. 1-6, 2012.

[24] S. Gaweł, M. Wardas, E. Niedworok, and P. Wardas, "Malondialdehyde (MDA) as a lipid peroxidation marker," Wiadomosci Lekarskie, vol. 57, no. 9-10, p. 453, 2004.

[25] E. Boyland and L. F. Chasseaud, "Glutathione S-aralkyltransferase," Biochemical Journal, vol. 115, no. 5, pp. 985-991, 1969.

[26] A. L. Wang and K. D. Tew, "Increased glutathione-Stransferase activity in a cell line with acquired resistance to nitrogen mustards," Cancer Treatment Reports, vol. 69, no. 6, pp. 677-682, 1985.

[27] G. Batist, A. Tulpule, B. K. Sinha, A. G. Katki, C. E. Myers, and K. H. Cowan, "Overexpression of a novel anionic glutathione transferase in multidrug-resistant human breast cancer cells," The Journal of Biological Chemistry, vol. 261, no. 33, pp. 15544-15549, 1986. 


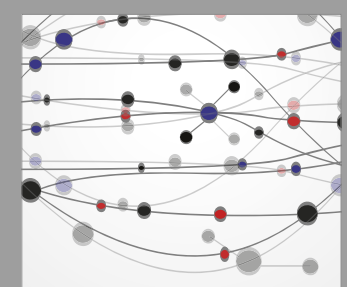

The Scientific World Journal
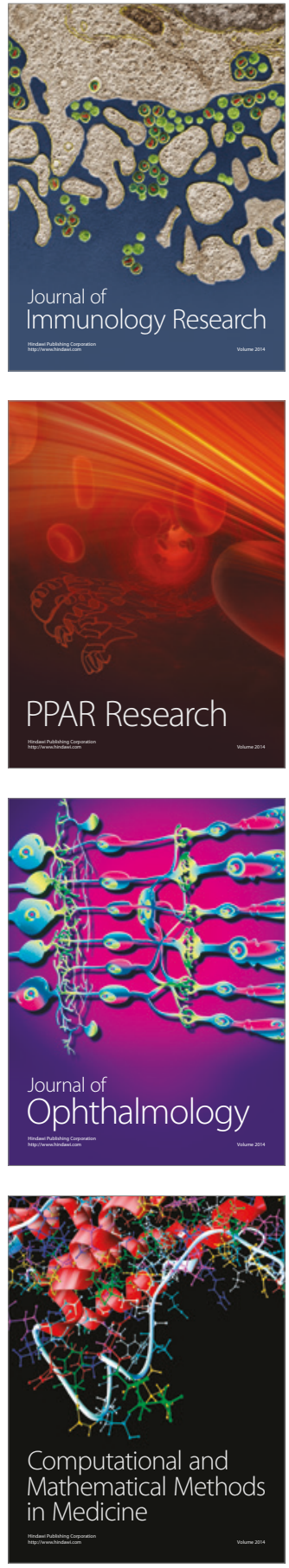

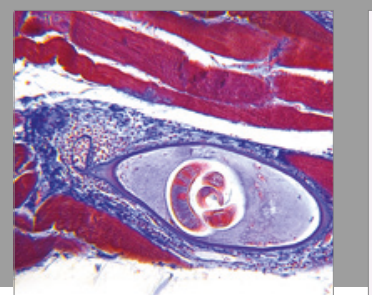

Gastroenterology Research and Practice
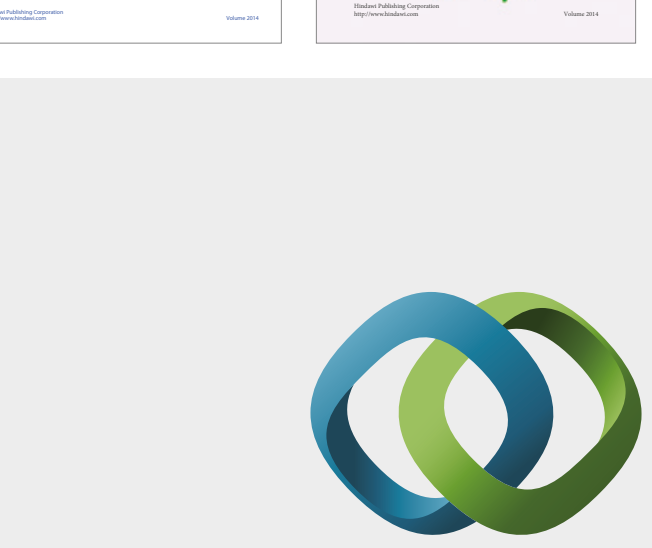

\section{Hindawi}

Submit your manuscripts at

https://www.hindawi.com
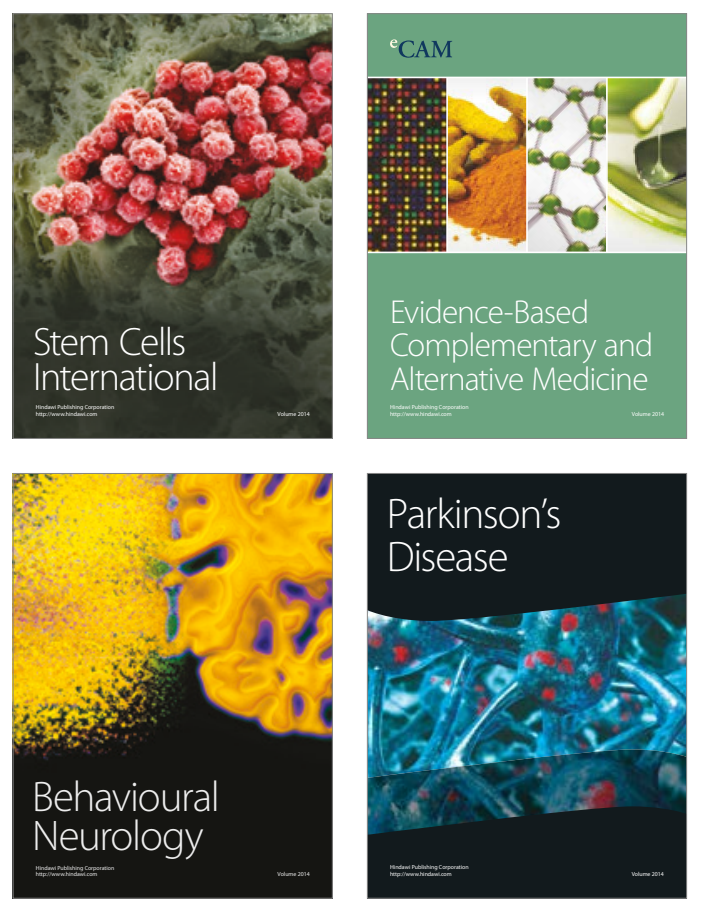
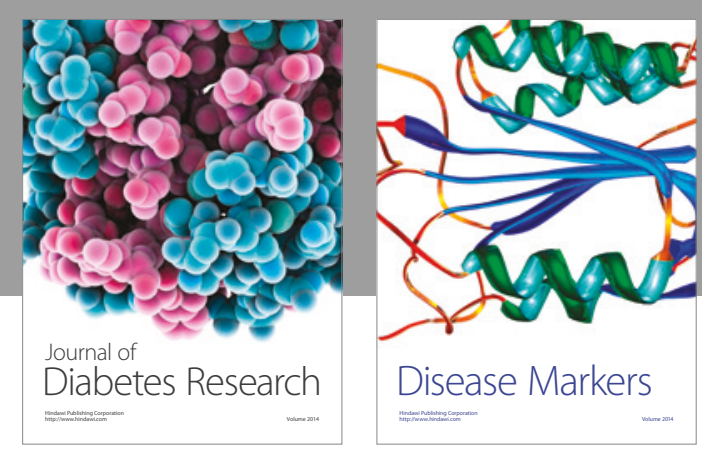

Disease Markers
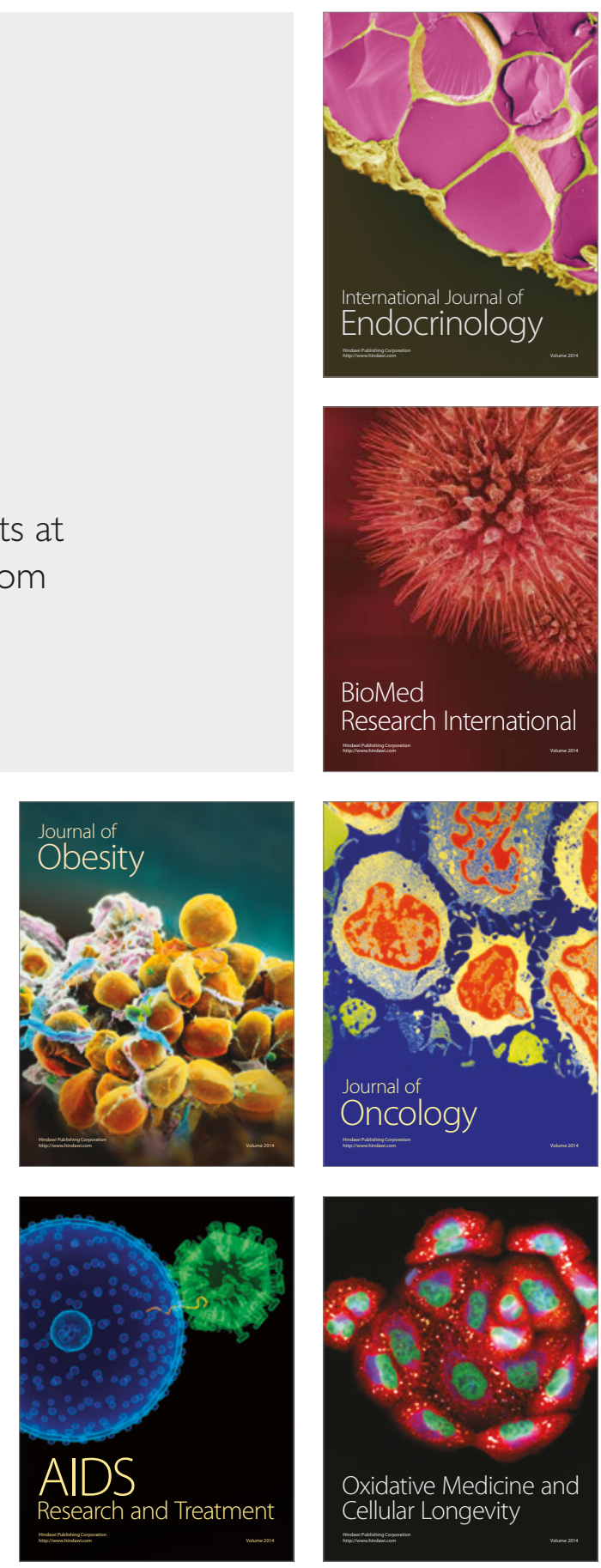